\title{
One-Pot Reaction for Synthesis of 1,2,3-Triazole Thioethers from lodotriazole, Sulfur and Alkylhalides/Tosylates
}

\author{
Bei Yang ${ }^{1,}$ a, Yi-ning Wen ${ }^{1}$, Zhen Jiang ${ }^{1}$, Lin-lin Zhang ${ }^{1}$, Pan $\mathrm{Yu}^{1}$, Ning-ning \\ Liu $^{1}$, Jian Zhang ${ }^{1}$ and Qin-pei Wu ${ }^{*}$ \\ ${ }^{1}$ Department of Applied Chemistry and Pharmaceutics, Beijing Institute of Technology, Beijing \\ 100081, China; \\ aybeilei@126.com, ㅁapwu@bit.edu.cn
}

Keywords: Triazole, Thioether, Copper, Halide, Tosylate, Reduction.

Abstract. A tandem procedure catalyzed by CuI has been developed for the synthesis of 1,2,3-triazole thioethers. Treatment of iodo 1,2,3-triazole with sulfur and followed by reduction with $\mathrm{NaBH}_{4}$ and alkylation with alkylhalides or tosylates in one-pot forms various triazole thioethers under mild conditions. This sequential reaction exhibits remarkable features, such as efficiency, broad substrate scope, good functional group tolerance and easy operation.

\section{Introduction}

Substituted triazole compounds have become potential targets for drug discovery, ${ }^{[1]}$ such as anticancer, ${ }^{[2]}$ antivirus, ${ }^{[3]}$ antibacteria, ${ }^{[4]}$ anti-fungus and anti-inflammation, ${ }^{[5]}$ and widespread potential applied in agrochemicals, polymers, dyes, and materials. ${ }^{[6]}$ The most common synthetic method is the well known Huisgen 1,3-dipolar cycloaddition of alkynes with azides for the construction of 1,4-disubstituted 1,2,3-triazole framework. ${ }^{[7]}$ However, the corresponding protocols for the synthesis of fully substituted 1,2,3-triazoles via Huisgen reaction remain a challenge ${ }^{[8]}$ due to the increased energy barrier $\left(270 \mathrm{~kJ} \mathrm{~mol}^{-1}\right),{ }^{[9]}$ particularly for the synthesis of 5-thio-1,2,3-triazoles. 1,2,3-Triazoles bearing a 5-sulfur substituent represent to be a series of useful molecules, ${ }^{[10]}$ for example, using as an excellent chiral ligand in organic synthesis ${ }^{[11]}$ and potential antifungal agents. ${ }^{[12]}$ Recently, Ding reported a method of Iridium-catalyzed cycloaddition of thioalkynes with azide $^{[13]}$. Herein we wish report a one-pot, tandem protocol for the synthesis of 1,2,3-triazole thioethers from readily available 5-iodo-1,2,3-triazoles, sulfur, alkylhalides or tosylates.

\section{Results and Discussion}

Based on the generality of the synthesis of thioethers starting from alkylhalides and thiols, ${ }^{[14]}$ we first investigated a one-pot reaction condition. 1-PMB-4-(methyl carbonyl)-5-iodo-1,2,3-triazole 1 readily prepared from azides and alkynes in the presence of CuI and $\mathrm{NBS}^{[15]}$ was used as a substrate to be treated with benzyl bromide and $\mathrm{Na}_{2} \mathrm{~S}$ or $\mathrm{NaHS}$ catalyzed with CuI. ${ }^{[16]}$ A number of trials, however, failed to form thioether 3 (Table 1, entry 1). Using thiourea ${ }^{[17]}$ and potassium ethyl xanthogenate $^{[18]}$ as a thiol surrogate, catalyzed respectively by $\mathrm{CuI}$ and $\mathrm{Cu}(\mathrm{OAc})_{2}-$ diamne ligand, led to no thioether 3 yet (Table 1, entries 2 and 3). 
Table 1. Optimization of the reaction conditions

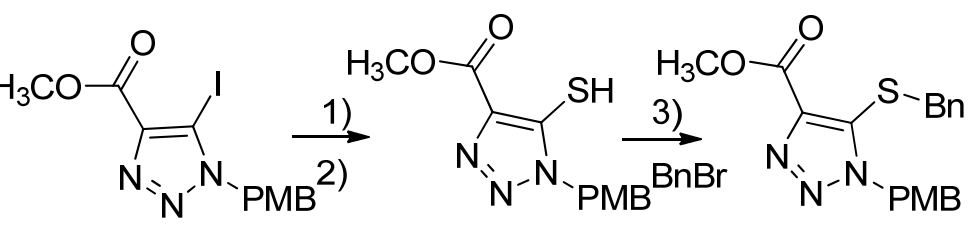

$1 \quad 2 \quad 3$

\begin{tabular}{|c|c|c|c|c|c|c|c|}
\hline Entry & Reaction conditions & Product & Yield/\% ${ }^{\mathrm{a}}$ & Entry & Reaction conditions & Product & Yield $/ \%{ }^{a}$ \\
\hline 1 & $\begin{array}{l}\mathrm{NaHS} / \mathrm{Na}_{2} \mathrm{~S}, \mathrm{CuI}, \\
\mathrm{BnBr}, \mathrm{DMF}, 80^{\circ} \mathrm{C}\end{array}$ & 3 & 0 & 5 & $\begin{array}{c}\text { 1). CuI, } \mathrm{S}, \mathrm{K}_{2} \mathrm{CO}_{3} \text {, } \\
\left.\mathrm{DMF}, 60^{\circ} \mathrm{C} ; 2\right) . \\
\mathrm{NaBH}_{4}, 0-40^{\circ} \mathrm{C}\end{array}$ & 2 & 61 \\
\hline 2 & $\begin{array}{c}\mathrm{S}=\mathrm{C}\left(\mathrm{NH}_{2}\right)_{2}, \mathrm{CuI}, \\
L \text {-proline, } \\
{ }^{\mathrm{t}} \mathrm{BuOK}, \mathrm{DMSO}, 90^{\circ} \mathrm{C}\end{array}$ & 3 & 0 & 6 & $\begin{array}{c}\text { 1). } \mathrm{CuI}, \mathrm{S}, \mathrm{K}_{2} \mathrm{CO}_{3} \text {, } \\
\left.\mathrm{DMF}, 60^{\circ} \mathrm{C} ; 2\right) . \\
\left.\mathrm{NaBH}_{4}, 0-40^{\circ} \mathrm{C} ; 3\right) . \\
\mathrm{BnBr}, \mathrm{rt}\end{array}$ & 3 & $\mathbf{8 0}^{\mathrm{b}}$ \\
\hline 3 & $\begin{array}{c}\text { KSCS(OEt), } \\
\mathrm{Cu}(\mathrm{OAc})_{2}-\text { diamne } \\
\text { ligand, DMF }\end{array}$ & 3 & 0 & 7 & $\begin{array}{c}\text { 1). } \mathrm{CuI}, \mathrm{S}, \mathrm{K}_{2} \mathrm{CO}_{3} \text {, } \\
\left.\mathrm{THF}, 60^{\circ} \mathrm{C} ; 2\right) . \\
\left.\mathrm{NaBH}_{4}, 0-40^{\circ} \mathrm{C} ; 3\right) . \\
\mathrm{BnBr}, \mathrm{rt}\end{array}$ & 3 & 57 \\
\hline 4 & $\begin{array}{l}\text { 1). CuI, } \mathrm{S}, \mathrm{K}_{2} \mathrm{CO}_{3} \text {, } \\
\left.\mathrm{DMF}, 90^{\circ} \mathrm{C} ; 2\right) . \\
\mathrm{NaBH}_{4}, 0-40^{\circ} \mathrm{C}\end{array}$ & 2 & 49 & 8 & $\begin{array}{c}\text { 1). CuI, S, } \mathrm{K}_{2} \mathrm{CO}_{3} \text {, } \\
\left.\mathrm{MeCN}, 60^{\circ} \mathrm{C} ; 2\right) . \\
\left.\mathrm{NaBH}_{4} 0-40^{\circ} \mathrm{C} ; 3\right) . \\
\mathrm{BnBr}, \mathrm{rt}\end{array}$ & 3 & 30 \\
\hline
\end{tabular}

a yield isolated.

${ }^{b}$ conditions: 1), CuI (10 mol\%), S (3 eq), $\mathrm{K}_{2} \mathrm{CO}_{3}$ (3 eq), DMF/THF/MeCN, $60^{\circ} \mathrm{C}$; 2), $\mathrm{NaBH}_{4}$ (portions, 2 eq), $0-40^{\circ} \mathrm{C}, 5$ h; 3), $\mathrm{BnBr}(1.5 \mathrm{eq})$, rt, overnight;

Bn: benzyl; PMB: 4-methoxybenzyl.

We then attempted to transform 5-iodo-1,2,3-triazole 1 into the corresponding 5-thio-1,2,3 -triazole 2 and then followed by alkylation with alkyl halides. Among the known approaches for preparation of aryl thiols, reductive cleavage of aryl disulfides proves to be applicable. ${ }^{[19]}$ Thus sulfur was employed to couple with iodotriazole 1 in the presence of $\mathrm{CuI}$ (10 mol\%) and followed by reduction with $\mathrm{NaBH}_{4}$ at $40^{\circ} \mathrm{C}$. To our delight, thiol 2 was obtained in $49 \%$ and the total yield for 2 was further increased by $61 \%$ as the first step was run at lower temperature, $60^{\circ \mathrm{C}}$ (Table 1 , entries 4 and 5). To make the procedure simple, benzyl bromide was added just after complete reduction without work-up and the expected thioether 3 was obtained in $80 \%$ isolated yield for the three-step consequent reaction (Table 1, entry 6). The efficiency of solvents including THF and MeCN was also screened and DMF gives rise to the highest efficiency (Table 1, entries 7 and 8).

Upon the optimized reaction conditions established, we set out to survey the scope of this one-pot reaction; a variety of alkyl halides and several 5-iodotriazoles had been examined. In most cases, this tandem reaction proceeded efficiently to give the corresponding 1,2,3-triazole thioethers, the yield was about $80 \%$.

To further examine the scope of this tandem reaction, alkylhalides were displaced with tosylates to run this thioetherifying reaction. As summarized in table 3, a number of thioethers were also formed smoothly in good to excellent yields from alkyl tosylates. Particularly, quite good reaction selectivity was observed as 2-fluoroethyl tosylate were employed in this process, namely, the tosylate group is substituted by sulfur to give fluoroethyl sulfide $\mathbf{3 e}$ in $56 \%$ yield (Table 2, entry 5). In the case of 2-bromoethyl tosylate, two products, thioether $3 \mathbf{f}$ (Table 2, entry 6) and $\mathbf{4}$ (Fig. 1), were formed. Triazole 4 is a reductive de-iodation product but not observed in the first two steps. Isopropyl tosylate was converted into the expected isopropyl thioether $\mathbf{3 g}$ in a $37 \%$ yield. 
Table 2. Synthesis of triazol thioethers from tosylates ${ }^{\mathrm{a}}$

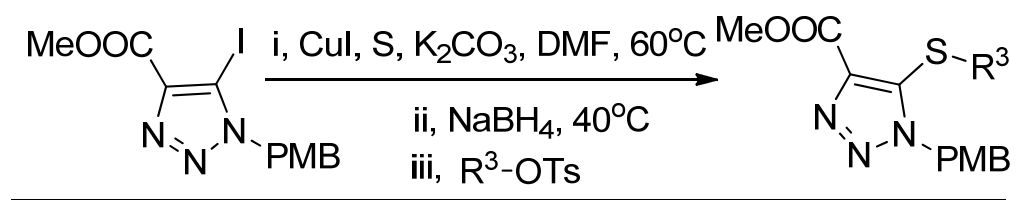

\begin{tabular}{cccc}
\hline Entry & $\mathbf{R}^{\mathbf{3}}$-OTs & product & Yield/\% $\mathbf{o}^{\mathbf{b}}$ \\
\hline $\mathbf{1}$ & $\mathrm{C}_{6} \mathrm{H}_{5} \mathrm{CH}_{2} \mathrm{CH}_{2}$-OTs & $\mathbf{3 a}$ & 62 \\
$\mathbf{2}$ & $\mathrm{CH}_{3} \mathrm{CH}_{2} \mathrm{CH}_{2} \mathrm{CH}_{2}-\mathrm{OTs}$ & $\mathbf{3 b}$ & 64 \\
$\mathbf{3}$ & $\mathrm{CH}_{3} \mathrm{CH}_{2}-\mathrm{OTs}$ & $\mathbf{3 c}$ & 61 \\
$\mathbf{4}$ & $\mathrm{CH}_{3} \mathrm{O} \mathrm{CH}_{2} \mathrm{CH}_{2}$-OTs & $\mathbf{3 d}$ & 69 \\
$\mathbf{5}$ & $\mathrm{FCH}_{2} \mathrm{CH}_{2}$-OTs & $\mathbf{3 e}$ & 65 \\
$\mathbf{6}$ & $\mathrm{BrCH}_{2} \mathrm{CH}_{2}$-OTs & $\mathbf{3 f}$ & 33 \\
$\mathbf{7}$ & $\left(\mathrm{CH}_{3}\right)_{2} \mathrm{CH}_{2}$-OTs & $\mathbf{3 g}$ & 37
\end{tabular}

${ }^{a}$ Conditions: 1 ), $\mathrm{CuI}\left(10 \mathrm{~mol} \%\right.$ ), $\mathrm{S}(3 \mathrm{eq}), \mathrm{K}_{2} \mathrm{CO}_{3}(3 \mathrm{eq})$, DMF, $60^{\circ} \mathrm{C}$; 2), $\mathrm{NaBH}_{4}$ (2 eq) added in portions, $0-40^{\circ} \mathrm{C}, 5 \mathrm{~h}$; 3), alkyl tosylate (1.3 eq), rt, overnight;

b yield isolated.<smiles></smiles>

4

Fig. 1. Triazole products

\section{Summary}

A one-pot reaction for efficient synthesis of triazole thioethers through the sequential reactions of iodotriazole with sulfur and alkyl halides/tosylates has been developed. In the presence of CuI, various alkyl halides and tosylates can participate in this efficient sulfidation reaction to furnish a wide range of triazole thioethers under mild conditions. This reaction exhibits high efficiency, broad substrate scope, good function tolerance and readily operation. Further detailed investigations of thiotriazoles on antiviral activity are underway.

\section{Experimental Section}

\section{General procedure for synthesis of thioethers}

To a solution of 5-iodo-1,2,3-triazole 1 (1.0 mmol), sulfur powder (3.0 eq) and $\mathrm{K}_{2} \mathrm{CO}_{3}(3.0 \mathrm{eq})$ in DMF (3 mL/mmol), CuI $(0.1 \mathrm{eq})$ was added. The reaction mixture was stirred at $60^{\circ} \mathrm{C}$ until 1 was completely consumed. The mixture was cooled by ice and $\mathrm{NaBH}_{4}(2.0 \mathrm{eq})$ was added in portions. After addition, the mixture was warmed up to $40^{\circ} \mathrm{C}$ and stirred for $5 \mathrm{~h}$. Alkyl halides or tosylates (2 eq) was added and stirred at room temperature overnight before saturated aqueous $\mathrm{NaHCO}_{3}$ was added. The mixture was extracted with $\mathrm{CH}_{2} \mathrm{Cl}_{2}$, and the organic layer was washed with brine, and dried over $\mathrm{Mg}_{2} \mathrm{SO}_{4}$. After removal of the solvent in vacuo, the residue was purified by flash chromatography eluted with ethyl acetate - petroleum ether $(2: 8, \mathrm{v} / \mathrm{v})$.

\section{Acknowledgments}

Financial support of this work by the National Natural Science Foundation of China (21172019) is appreciated. 


\section{References}

[1] S. G. Agalave, S. R. Maujan, V. S. Pore, Chem. Asian J. 2011, 6, 2696-2718.

[2] R. Pingaew, S. Prachayasittikul, S. Ruchirawat, V. Prachayasittikul, Med. Chem. Res. 2014, 23, 1768-1780.

[3] M. d. L. G. Ferreira, L. C. S. Pinheiro, O. A. Santos-Filho, M. D. S. Pecanha, C. Q. Sacramento, V. Machado, V. F. Ferreira, T. M. L. Souza, N. Boechat, Med. Chem. Res. 2014, 23, 1501-1511.

[4] S. R. Patpi, L. Pulipati, P. Yogeeswari, D. Sriram, N. Jain, B. Sridhar, R. Murthy, A. T. Devi, S. V. Kalivendi, S. Kantevari, J. Med. Chem. 2012, 55, 3911-3922.

[5] A. K. Jordão, V. F. Ferreira, E. S. Lima, M. C. B. V. de Souza, E. C. L. Carlos, H. C. Castro, R. B. Geraldo, C. R. Rodrigues, M. C. B. Almeida, A. C. Cunha, Bioorg. Med. Chem. 2009, 17, 3713-3719.

[6] P. L. Golas, K. Matyjaszewski, Chem. Soc. Rev. 2010, 39, 1338-1354.

[7] H. C. Kolb, M. G. Finn, K. B. Sharpless, Angew. Chem., Int. Ed. 2001, 40, 2004-2021.

[8] H. Shu, S. Izenwasser, D. Wade, E. D. Stevens, M. L. Trudell, Bioorg. Med. Chem. Lett. 2009, 19, 891-893.

[9] C. Spiteri, J. E. Moses, Angew. Chem. Int. Ed. 2010, 49, 31-33.

[10] M. Singer, M. Lopez, L. F. Bornaghi, A. Innocenti, D. Vullo, C. T. Supuran, S.-A. Poulsen, Bioorg. Med. Chem. Lett. 2009, 19, 2273-2277.

[11] M. Kato, T. Nakamura, K. Ogata, S-i.Fukuzawa, Eur. J. Org. Chem. 2009, 5232-5238.

[12] Y. Morzherin, P. E. Prokhorova, D. A. Musikhin, T. V. Glukhareva, Z. Fan, Pure Appl. Chem. 2011, 83, 715-722.

[13] S. Ding, G. Jia, J. Sun, Angew. Chem. Int. Ed. 2014, 53, 1877-1880.

[14] Review and example of Synthesis of thioethers: a) H.-J. Xu, Y.-F. Liang, X.-F. Zhou, Y.-S. Feng, Org. Biomol. Chem. 2012, 10, 2562-2568.

[15] L. Li, G. Zhang, A. Zhu, L. Zhang, J. Org. Chem. 2008, 73, 3630-3633.

[16] D. Ma, S. Xie, P. Xue, X. Zhang, J. Dong, Y. Jiang, Angew. Chem., Int. Ed. 2009, 48, 4222-4225.

[17] T. Ramana, P. S aha, M. Das, T. Punniyamurthy, Org. Lett. 2010, 12, 84-87.

[18] D. J. C. Prasad, G. Sekar, Org. Lett. 2011, 13, 1008-1011.

[19] a) N. Jarkas, R. J. Voll, L. Williams, J. Votaw, M. Owens, M. M. Goodman, J. Med. Chem. 2008, 51, 271-276; b) H. Shinkai, K. Maeda, T. Yamasaki, H. Okamoto, I. Uchida, J. Med. Chem. 2000, 43, 3566-3570; c) R. Amos, S.Fawcett, J. Org. Chem. 1984, 49, 2637-2639; d) Y. Jiang, Y. Qin, S. Xie, X. Zhang, J. Dong, D. Ma, Org. Lett. 2009, 11, 5250-5253. 